\title{
Leitura de história em voz alta: proposta de uma intervenção fonoaudiológica com
}

\section{professores}

\author{
The effects of a story-reading-aloud program on the vocal expressiveness of kindergarten teachers \\ Leer historias en voz alta: propuesta de intervención del logopeda con los profesores
}

Recebido: 01/09/2021 | Revisado: 10/09/2021 | Aceito: 23/11/2021 | Publicado: 03/12/2021

Cintia Ortegosa Cordeiro

ORCID: https://orcid.org/0000-0001-9187-3998 Pontifícia Universidade Católica de São Paulo, Brasil

E-mail: ciortegosa@gmail.com

Ana Paula da Silva Tozzo

ORCID: https://orcid.org/0000-0002-5205-1497 Pontifícia Universidade Católica de São Paulo, Brasil

E-mail: aptozzo@yahoo.com.br

Léslie Piccolotto Ferreira

ORCID: https://orcid.org/0000-0002-3230-7248 Pontifícia Universidade Católica de São Paulo, Brasil E-mail: lesliepf@pucsp.br

\begin{abstract}
Resumo
Objetivo: investigar os efeitos de uma intervenção de leitura de histórias em voz alta com professoras de educação infantil. Método: três professoras participaram de intervenção com registro de gravação (gravador Marantz, microfone AKG) de leitura em voz alta do livro: "Bruxa Bruxa! Por favor venha a minha festa", nos momentos pré e pósintervenção. As amostras de leitura foram digitalizadas em formato wav., editadas e etiquetadas no Praat. O trecho "Gato, Gato! Por favor, venha a minha festa" foi destacado para análise. Foram extraídas medidas acústicas da duração desse enunciado e 35 professores juízes, ouviram as amostras sem o conhecimento de quais situações eram pré ou pós intervenção. Esses registraram as impressões auditivas classificando-as como iguais ou diferentes. Caso fossem diferentes, escolheram a mais: cativante, motivante, interessante, melodiosa, clara e pausada. Verificou-se os conhecimentos obtidos das participantes, por meio de uma ficha de avaliação após a intervenção. Resultados: observou-se aumento da duração do enunciado nas três participantes depois da intervenção. A maioria dos juízes notou diferença estatisticamente significativa entre as leituras em todas as participantes, considerando mais adequado o momento pós-intervenção. As professoras referiram efeitos positivos da intervenção, percebidos em aspectos de expressividade oral trabalhados. Após a intervenção revelaram terem obtido conhecimentos em relação à expressividade e colocaram esses em prática. Conclusões: os juízes perceberam diferença significativa nas leituras e julgaram melhor o momento pós-intervenção fonoaudiológica, principalmente quanto a estar mais pausada, melodiosa, interessante, cativante e motivadora para o público infantil. O programa de intervenção gerou efeito positivo nas participantes.
\end{abstract}

Palavras-chave: Voz; Expressividade; Leitura.

\begin{abstract}
Purpose: to investigate the effects of a story-reading-aloud program on some expressiveness features in kindergarten teachers. Methods: Three preschool teachers were engaged in a simulated story-reading-aloud task and produced narrations as they normally do with their students. The narrations were audio-recorded using a Marantz professional tape recorder and an AKG microphone. Each narration was digitized individually using Praat. The effects of the programs were assessed doing the same recording procedures after the intervention. Thirty five kindergarten experienced teachers listened to the speech samples from the different moments (before and after intervention) and made comparative judgments regarding pauses, clarity, interesting, motivation and melody. Results: Results revealed that the teachers modified their speech at multiple levels. As a group, the participants demonstrated increased enunciation duration. The majority of the judges noticed statistically significant differences between the reading samples in all participants, considering the moment after intervention from the teachers as more: interesting, motivational, paused and melodic. The teachers referred positive effects from the intervention, referred in every aspect of oral expressiveness practiced. The participants reveled obtaining new vocal expressiveness knowledge after intervention and put this is use during in their work activities. Conclusion: Enunciation duration significantly increased when reading the stories aloud after intervention. The kindergarten experienced teachers, who listened the samples, noticed statistically significant differences between the reading samples and judged the moment after
\end{abstract}


intervention as the best, mainly as being more paused, melodic, interesting, and motivating for children. The intervention program had a positive effect among the participants.

Keywords: Voice; Expressiveness; Reading.

\begin{abstract}
Resumen
Objetivo: investigar los efectos de una intervención de lectura de cuentos en voz alta con profesores de educación infantil. Método: tres profesores participaron con un disco de grabación (grabadora Marantz, micrófono AKG) para leer en voz alta el libro: “¡Bruja, Bruja! Por favor ven a mi fiesta”, en los momentos previos y posteriores a la intervención. Las muestras de lectura fueron digitalizadas en formato wav., Editadas y etiquetadas en Praat. El extracto “¡Gato, Gato! Por favor, ven a mi fiesta”, se destacó para su análisis. Se extrajeron medidas acústicas de la duración de esta declaración y 35 jueces docentes escucharon las muestras sin saber qué situaciones eran pre o post intervención. Registraron las impresiones auditivas, clasificándolas como iguales os diferentes. En los diferentes, eligieron los más cautivadores, motivadores, interesantes, melodiosos, claros y pausados. El conocimiento de los participantes se registró en un formulario de evaluación después de la intervención. Resultado: Se observó un aumento en la duración de la declaración en los tres participantes después de la intervención. La mayoría de los jueces notaron una diferencia estadísticamente significativa entre las lecturas en todos los participantes, considerando el momento post-intervención más apropiado. Destacaron lo pausado, melodioso, interesante, cautivador y motivador para el público infantil. Los docentes reportaron efectos positivos de la intervención, percibidos en aspectos de expresividad oral trabajados. Revelaron que habían obtenido conocimientos en relación a la expresividad al ponerla en práctica. Conclusión: el programa de intervención tuvo un efecto positivo en los participantes.
\end{abstract}

Palabras clave: Voz; Expressividade; Lectura.

\title{
1. Introdução
}

Leitura para crianças pequenas é um tema cada vez mais popular. Essa prática, além de realizada pelos pais, e comum na educação infantil por professores, tem sido adotada também por leitores em espaços públicos como bibliotecas, livrarias e salas de leitura. Entretanto, o cotidiano escolar é um lugar significativo em que se encontram instrumentos para se realizar transformações no sentido da constituição de leitores. Combs e Beach (1994, p. 47) alegam que a narração de histórias é essencial para a construção de significados por crianças que estão no início da escolarização. Cabe, portanto, aos professores, a possibilidade de dar um rumo ao enredo.

Um estudo, com crianças de três a cinco anos, mostrou que o estímulo precoce à leitura influencia na atividade cerebral, mudando a maneira como o cérebro processa as histórias e aumentando as chances de formar um leitor ávido. Quanto mais consistente a exposição à leitura, mais áreas cerebrais que suportam o processo semântico (atribuição de significado a frases e palavras) são ativadas pela narrativa (Hutton, 2017).

Mais recentemente, outro estudo trouxe contribuições relevantes ao analisar os efeitos benéficos da leitura no cérebro de crianças que ouviam histórias para promover a diminuição de tempo de exposição de telas. A pesquisa deteve-se nos efeitos da leitura em voz alta na atividade cerebral por meio de análise de ressonância magnética do cérebro de 69 crianças de educação infantil entre 3 a 5 anos de idade. Os resultados revelaram que crianças que permaneciam mais tempo nas telas desenvolveram menos massa branca em áreas cerebrais importantes para a linguagem e literacia do que aquelas que utilizaram menos telas (Hutton et al., 2020).

Os autores em apreço acrescentam que, leitura em voz alta com livros ilustrados proporcionam ativações importantes no cérebro. Concluíram que ouvir as palavras lidas por um adulto, abre caminhos para a linguagem enquanto que animações hiper estimulam as redes visuais. A combinação de figuras estáticas com palavras gera uma integração ótima entre linguagem auditiva e visual nessa idade.

A leitura é interação dinâmica, uma resposta às solicitações do texto, um trabalho de interpretação. O texto fixo em sua letra, não é o mesmo se mudarem os dispositivos do suporte que o transmite a seus leitores, a seus ouvintes ou a seus espectadores (Chartier, 1997). 
Ler em voz alta é uma atividade complexa que requer a coordenação de diversas tarefas ao mesmo tempo. Para a conquista dessas, muitas habilidades são requisitadas para que a fluência da leitura pareça sem esforço e natural (Logan, 1997). $\mathrm{Na}$ experiência docente em cursos de educação infantil é possível perceber e experimentar a multiplicidade de recursos de que o professor se vale para alcançar os objetivos propostos.

A prosódia estabeleceria a ponte inicial, relacionando som e sentido. Há mudanças de posição do infante com relação às modulações de voz da mãe. Assim, é o primeiro veículo da organização das formas linguísticas, sobretudo por meio dos sistemas de ritmo e entoação. É aquela que se caracteriza como melódica/ entoacional por excelência (Scarpa, 2005). Portanto, a prosódia precisa ser trabalhada também na escola, uma vez que é iniciada cedo na vida da criança.

Madureira (2011) entende que expressividade da fala ou oral se constrói a partir das interações que se estabelecem entre elementos segmentais (vogais e consoantes) e prosódicos (ritmo, entoação, qualidade de voz, taxa de elocução, pausas e padrões de acento) e das relações que se estabelecem entre som e sentido. Já em 1961, Bolinger alegava que, ao aumentar o conhecimento sobre a prosódia durante a leitura em voz alta, essa iria mudar a expressividade da leitura. Assim, prosódia se refere ao ritmo, entoação e pausa na fala e serve para uma variedade de funções linguísticas e afetivas. Entender que cada som pode resultar em diferentes sentidos mudaria a forma de realizar a leitura em voz alta de um texto.

No que diz respeito ao papel das habilidades prosódicas, Magriet et al. (2018) mostraram as contribuições na compreensão da leitura em voz alta. Os autores analisaram a performance da prosódia durante a leitura de textos em voz alta em alunos do $5^{\circ}$ ano. Os resultados revelaram que dificuldades de compreensão estão relacionadas com as baixas taxas de desempenho prosódico. Portanto, a prosódia da fala justifica as variações de compreensão do que foi lido em voz alta. Essa pesquisa corrobora o pressuposto de que ler em voz alta não envolve apenas a decodificação das palavras, mas para uma boa compreensão é necessária uma boa prosódia.

Um estudo desenvolvido por Paz (2007) com alunos da $2^{\mathrm{a}}, 5^{\mathrm{a}}$ e $7^{\mathrm{a}}$ séries de educação fundamental, que analisou a preferência para ouvir história, revelou que $90 \%$ dos alunos das séries iniciais gostam de ouvir história, enquanto nas outras séries o percentual sofreu um declínio. Uma vez que junto aos da $7^{\text {a }}$ série foi registrado um percentual de apenas $50 \%$. Os autores registraram, ainda, que cerca de $80 \%$ dos alunos da $2^{\mathrm{a}}$ série entendem melhor as histórias contadas pela professora do que quando leem sozinhos, e todos se interessam em buscar outras histórias do mesmo tipo das contadas pela professora, efetivando a contribuição da contação de histórias na formação de novos leitores.

A leitura em voz alta aparece como uma atividade com "efeito de produção". No trabalho desenvolvido por Forrin e Macleod (2018), ler e ouvir o que se está lendo é uma medida duplamente ativa "um ato motor (fala) e uma entrada auditiva autorreferencial". Os trechos ganham distinção, fixando suas marcas na memória de longo prazo. Este ato, realizado reiteradas vezes, operacionaliza a memorização de passagens longas. Tal feito mostra o impacto relevante da leitura em voz alta em áreas do processamento auditivo como a memória.

Ler com expressividade é hoje um componente integral da fluência de leitura (Hudson, 2005). Apesar de haver muitas pesquisas clínicas sobre voz, realizadas por fonoaudiólogos, estudos com o foco em expressividade oral têm um número reduzido na literatura consultada, quando comparados aos com tema de saúde e cuidados vocais. Propostas de intervenções com foco na expressividade oral são registradas mais em cursos técnicos e de graduação para profissionais da voz como por exemplo, com repórteres (Trindade \& Ferreira, 2008), com radialistas (Morais, 2010), e com telejornalistas (Azevedo et al., 2009).

Cabe destacar que a expressividade oral como tema de estudo é uma forma de atuação para além do contexto clínicoterapêutico, e esse trabalho é definido de diferentes formas: assessoria fonoaudiológica, aprimoramento ou educação vocal, estética vocal, e ainda treinamento (Ferreira et al., 2012). Os elementos expressivos mais importante são as características de longo prazo ou quase predominantes, em situação coloquial e, no caso de professor, em destaque nesta pesquisa, como 
atividade profissional. São elas: qualidade de voz, loudness, pitch, taxa de elocução, alongamentos de segmentos, segmentos marcados, sotaque (ou regionalismo), pausas entre outros (Viola \& Ferreira, 2016). Ler com expressividade é hoje um componente integral da fluência de leitura (Hudson, 2005). Apesar de haver muitas pesquisas clínicas sobre voz, realizadas por fonoaudiólogos, estudos com o foco em expressividade oral têm um número reduzido na literatura consultada, quando comparados aos com tema de saúde e cuidados vocais. Propostas de intervenções com foco na expressividade oral são registradas mais em cursos técnicos e de graduação para profissionais da voz como por exemplo, com repórteres (Trindade \& Ferreira, 2008), com radialistas (Morais, 2010), e com telejornalistas (Azevedo et al., 2009).

Cabe destacar que a expressividade oral como tema de estudo é uma forma de atuação para além do contexto clínicoterapêutico, e esse trabalho é definido de diferentes formas: assessoria fonoaudiológica, aprimoramento ou educação vocal, estética vocal, e ainda treinamento (Ferreira et al., 2012). Os elementos expressivos mais importante são as características de longo prazo ou quase predominantes, em situação coloquial e, no caso de professor, em destaque nesta pesquisa, como atividade profissional. São elas: qualidade de voz, loudness, pitch, taxa de elocução, alongamentos de segmentos, segmentos marcados, sotaque (ou regionalismo), pausas entre outros (Viola \& Ferreira, 2016).

Quanto mais instrumentalizado o professor estiver para revelar suas intenções e emoções por meio de sua voz dentro da história pela interpretação, mais interessante será sua atuação junto às crianças. Dessa forma, parte-se da hipótese de que professores expostos a uma oficina em que aspectos de expressividade oral seriam trabalhados teriam condições de produzir ao final dela leituras em voz alta com diversos sons, e, portanto, produzindo diferentes sentidos. Acredita-se que, o exercício de "simulação" de leitura de histórias, compartilhadas com o grupo de professores, de uma forma diferente das que estão acostumados a realizar, irá estimular mudanças positivas. Frente à confirmação da mesma, iniciativas dessa natureza poderão ser apresentadas a professores interessados em melhorar a sua performance na atividade de leitura em voz alta.

O objetivo deste estudo foi investigar os efeitos de uma intervenção de leitura de histórias em voz alta com professoras de educação infantil.

\section{Metodologia}

Esta pesquisa foi aprovada pelo Comitê de Ética em Pesquisa (número do CAAE: 39281414.8.0000.5482). Primeiramente a proposta foi apresentada ao diretor de uma escola municipal de educação infantil de São Paulo. Os professores dessa escola foram convidados a participar deste estudo e os que aceitaram foram informados sobre os objetivos e procedimentos da pesquisa. Antes do início das atividades, assinaram o Termo de Consentimento Livre e Esclarecido mediante a leitura prévia e esclarecimento de dúvidas.

Quanto ao método, trata-se de um estudo prospectivo de intervenção. A perspectiva intervencionista permite avaliar o impacto na ocorrência do desfecho do grupo avaliado. É o padrão de excelência em estudos que pretendem avaliar o efeito de uma intervenção no curso de uma situação clínica (Nedel \& Silveira, 2016). Quanto ao caráter prospectivo, permite que o estudo seja conduzido a partir do momento presente e caminha em direção ao futuro (Hochman et al., 2005).

Conforme explicitado a seguir, esta pesquisa realizou coleta de dados antes e depois de uma intervenção (oficina composta de seis encontros) proposta a professores de educação infantil.

Seleção dos sujeitos:

Inicialmente sete voluntários, todos do sexo feminino mostraram interesse em participar desta pesquisa, ou seja, frequentar a oficina. As professoras que, por quaisquer motivos, ficaram impossibilitados de comparecer a todos os seis encontros dessa oficina puderam continuar participando do trabalho, porém os seus dados foram excluídos da análise. Os critérios de inclusão foram atuar com educação infantil e disponibilidade. 
Assim, das sete voluntárias foram analisados os dados referentes a três participantes, denominadas P1, P2 e P3, que além de participar da oficina, foram solicitadas a realizar uma mesma leitura em voz alta, em dois momentos, a saber, antes e depois da intervenção, assim como responder a questões referentes a dados sócio demográficos e de situação funcional (nome, sexo, idade e tempo de atuação com educação infantil). Para coleta de dados referente à leitura em voz alta, foi selecionado o livro Bruxa, Bruxa venha à minha festa (Druce, 1995). Os critérios utilizados para escolha desse livro foram: texto curto considerando o tempo de leitura; presença de elementos adequados para faixa etária de educação infantil, como imagens grandes e realistas que ocupam todas as páginas incluindo frases curtas e repetitivas; variedade de personagens; diálogos e estrutura de textos favoráveis para verificação prosódica dos padrões de entoação e visualização das curvas melódicas vocais.

As gravações da leitura em voz alta ocorreram nos momentos pré e pós-intervenção fonoaudiológica (denominada oficina), ou seja, no primeiro e no sexto encontros, em condições semelhantes quanto ao texto (para garantir a homogeneidade do material fonético). As duas coletas de amostra de leitura foram registradas em gravador da marca Marantz. Nesses dois momentos cada participante foi orientada a permanecer sentada, com microfone AKG (modelo MPA III micro mic phanton) posicionado a uma distância de $10 \mathrm{~cm}$ da boca, num ângulo de aproximadamente 60 graus. No momento pré-intervenção, as professoras tiveram contato com o livro antes da gravação e foi solicitado que lessem primeiro para se familiarizarem com o texto, e em seguida, ler como habitualmente fazem para seus alunos em voz alta, ocasião em que foi realizada a áudiogravação.

A oficina foi realizada em um total de seis encontros de uma hora (total de seis horas) e oferecida na própria escola em sala destinada a reuniões. Nessa intervenção os participantes tiveram a oportunidade de experimentar a realização de leitura em voz alta com a utilização de diferentes parâmetros de expressividade oral, a saber: pausas, articulação, ressonância, pitch e intensidade. A finalidade foi aplicá-los na simulação de apresentações de leituras para crianças. Foram trabalhados também aspectos relacionados à respiração (em especial a coordenação pneumofonoarticulatória) (Ferreira, 2015)

Sempre que possível, as participantes foram alertadas quanto à simultaneidade de parâmetros tanto referentes à expressividade oral quanto aos gestuais/corporais e também de aspectos de bem-estar vocal. Todos os encontros foram áudio gravados para subsidiar a pesquisa e servir como estratégia denominada de auto confrontação (Borrego, 2017). O intuito dessa estratégia foi facilitar que o sujeito falasse sobre si mesmo a partir do que via. Assim, as participantes tiveram a oportunidade de ouvir suas próprias performances e puderam fazer um intercâmbio das impressões das mesmas no grupo.

As duas coletas de amostra de leitura (gravadas pré e pós-intervenção) foram digitalizadas em formato wav em registro mono e editadas no computador Dell XPS Intel core $i 7 \mathrm{com}$ assessoria de profissional técnico de rádio. As amostras foram organizadas, separadamente, considerando o material de cada professora, identificada em cada arquivo como P1, P2 e P3. O corpus contou com cinco trechos de leitura coletados nas mesmas condições, nos dois momentos (pré e pós intervenção) das três professoras, editados, e devidamente etiquetados no PRAAT (Boersma \& Weenik, 2001). Contudo, apenas o trecho correspondente a frase "Gato, Gato, por favor venha a minha festa", o terceiro dos cinco trechos, foi destacado para análise por representar a modalidade de pedido e estar na página três, após dois enunciados, fato que permitia a motivação para elaboração de mais recursos de vozes das personagens.

Para garantir a forma cega de avaliação, ou seja, sem o conhecimento por parte de avaliador de que houve uma intervenção e, portanto, quais eram as situações pré ou pós-intervenção fonoaudiológica, o material de cada professor foi sorteado e denominado gravação 1 (pré ou pós de acordo com o sorteio) e 2 (pré ou pós também de acordo com o sorteio) para que de forma aleatória o mesmo fosse submetido à audição perceptivo-auditiva. As combinações das três professoras ficaram assim distribuídas, de acordo com o resultado do sorteio: P2=pré pós, totalizando 11 segundos, P3=pós pré, totalizando 9 segundos, e P1=pós pré, totalizando 15 segundos (tempo médio das participantes = 11,6 segundos). 
$\mathrm{Na}$ análise dos dados referentes à coleta de amostra de leitura em voz alta foram submetidos à avaliação de sentido e inspeção acústica.

- Avaliação perceptivo-auditiva e de sentido: 35 juízes ouviram as amostras de leitura. Esse grupo foi composto por professores de educação infantil e, portanto, praticantes de leitura para crianças. Esses foram convidados a participar desta avaliação. Esses sujeitos, no papel de avaliadores, receberam via internet por meio da plataforma "Survey Gizmo" (disponível em http://www.surveygizmo.com), o material editado, segundo descrito anteriormente. A apresentação das imagens aos avaliadores foi feita para todos numa mesma sequência (P2, P3 e P1) e de forma cega, ou seja, sem o conhecimento de quais eram as situações pré ou pós-intervenção fonoaudiológica. Os juízes analisaram individualmente as amostras de cada professor e depois de ouvir o material registraram se as gravações de leitura (1 e 2) eram iguais ou diferentes. No caso de relatarem serem diferentes, foram apresentados os descritores: cativante, motivante, interessante, melodiosa, clara e pausada. Foi solicitada a escolha de qual das duas gravações se destacava quanto a cada um dos descritores.

- Inspeção acústica - Foi realizada inspeção acústica das amostras de leitura das três professoras, considerando material editado e devidamente etiquetado no PRAAT (Boersma \& Weenik, 2001) www.praat.org - software de livre distribuição para pesquisa em fonética acústica. O mesmo trecho enviado para os juízes "Gato, gato, por favor venha a minha festa" foi submetido à medida acústica de duração do enunciado (DE). O tempo de duração do enunciado (pré e pós-intervenção) de cada participante foi considerado em segundos. Na Figura 1 encontra-se um exemplo de imagem acústica do trecho desse enunciado de leitura do sujeito P2 pré e pós- intervenção.

- Figura 1. Exemplo de leitura do enunciado "Gato gato, por favor venha a minha festa" pré e pós intervenção

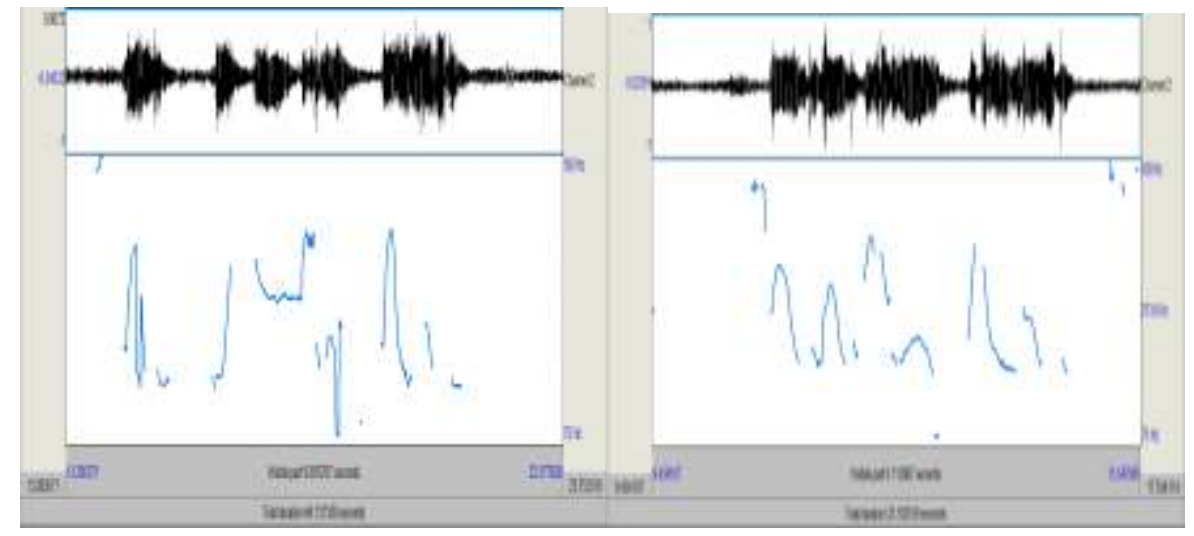

Fonte: Autores.

Para análise estatística, foi realizada a análise descritiva dos dados por meio de frequências absolutas e relativas, medidas de tendência central (média e mediana) e dispersão (desvio-padrão, valores mínimo e máximo). Identificou-se a distribuição das idades e o tempo de trabalho na educação infantil dos 35 juízes participantes da pesquisa e o número e percentual de juízes segundo a comparação entre os professores na classificação da leitura pré e pós a intervenção. Na comparação entre os professores foi utilizado o teste de associação pelo Qui-quadrado e sua Partição. Para avaliar a mudança nas características da fala - cativante, motivante, interessante, clara, melodiosa e pausada - das três professoras observadas, segundo a opinião dos 35 juízes, aplicou-se o teste de McMenar.

Foi realizada medida acústica de duração do enunciado (DE) das três participantes (pré e pós-intervenção). 
Assumiu-se um nível descritivo do de 5\% (p<0,05) para significância estatística. Os dados foram digitados na plataforma SurveyGizmo, transportados para Excel e analisados no programa StatisticalPackage for the Social Sciences (SPSS) versão 17.0 para Windows.

Ao final do processo de intervenção, foi entregue uma ficha de avaliação das oficinas para cada uma das três professoras participantes, a fim de que elas descrevessem os aspectos referentes aos recursos vocais trabalhados na intervenção, que mais aproveitaram bem como os aspectos que julgaram positivos e negativos do processo. Objetivou-se assim, verificar os conhecimentos obtidos em relação à respiração, articulação, ressonância, pitch e intensidade bem como os aspectos positivos e negativos da proposta. Esses dados foram analisados de forma descritiva.

\section{Resultados}

A Tabela 1 apresenta a caracterização do perfil das três participantes deste estudo, que apresentaram média de idade de 40,3 anos e de tempo de docência em educação infantil de 19 anos. Com relação à inspeção acústica do tempo de duração do enunciado, verificou-se que todas aumentaram no momento pós intervenção, quando esse foi comparado ao pré.

Tabela 1. Idade, tempo de docência e duração do enunciado (DE), nos momentos pré e pós intervenção das participantes.

\begin{tabular}{l|c|c|c|c}
\cline { 2 - 4 } \multicolumn{1}{c|}{} & P1 & P2 & P3 & Mediana \\
\hline Idade (anos) & 43 & 35 & 43 & 40 \\
\hline & & & & \\
\hline tempo de docência(anos) & 23 & 18 & 16 & 19 \\
\hline DE-Pré (segundos) & 6,455 & 6,113 & 5,909 & 6.15 \\
\hline & & & & \\
\hline DE-Pós (segundos) & 12,944 & 9,097 & 6,915 & 9.63 \\
\hline & & & & \\
\hline
\end{tabular}

Fonte: Autores.

Os 35 juízes que registraram as impressões auditivas das leituras das três professoras eram em sua maioria, do sexo feminino (88,6\%). Identifica-se (Tabela 2) a distribuição da média de idade e o tempo de trabalho em educação infantil desses juízes.

Tabela 2. Análise quantitativa das variáveis idade e tempo de trabalho na educação infantil dos juízes.

\begin{tabular}{l|c|c|c|c|c}
\hline \multicolumn{1}{c|}{ Variáveis } & $\bar{X}$ & (dp) & Mediana & Mínimo & Máximo \\
\hline Idade (anos) & & & & & \\
\hline & 37,6 & $(6,5)$ & 36 & 27 & 54 \\
\hline $\begin{array}{l}\text { Tempo de trabalho com educação } \\
\text { infantil (anos)* }\end{array}$ & 9,0 & $(5,9)$ & 8 & 1 & 24 \\
\hline
\end{tabular}

* dados referentes a 31 juízes, pois 4 trabalharam com leitura, mas não na educação infantil. Fonte: Autores.

Na Tabela 3 e no Gráfico 1, observa-se na comparação entre os professores (P1, P2 e P3), segundo os juízes que classificaram a leitura dos professores em momento pré e pós-intervenção, julgando-as como iguais ou diferentes, que houve 
associação estatisticamente significativa $(<0,001)$ entre as leituras e o professor. O P3 apresentou o menor percentual de leitura classificada como diferente $(65,7 \%)$.

Tabela 3. Número e percentual de juízes segundo a comparação entre os professores na classificação da leitura Pré e Pós a intervenção.

\begin{tabular}{l|c|c|c|c}
\hline \multicolumn{1}{c|}{ Leituras } & P1 & P2 & P3 & p \\
\hline & $\mathbf{n}(\boldsymbol{\%})$ & $\mathbf{n}(\boldsymbol{\%})$ & $\mathbf{n}(\boldsymbol{\%})$ & \\
\hline Iguais & & & & \\
\hline & $1(2,9)$ & $2(5,7)$ & $12(34,3)$ & $<0,001$ \\
\hline Diferentes & $34(97,1)$ & $33(94,3)$ & $23(65,7)$ & \\
\hline & & & & \\
\hline Total & $35(100,0)$ & $35(100,0)$ & $35(100,0)$ & \\
\hline
\end{tabular}

Fonte: Autores.

Gráfico 1. Percentual de juízes que classificaram as leituras pré e pós aintervenção, segundo professores.

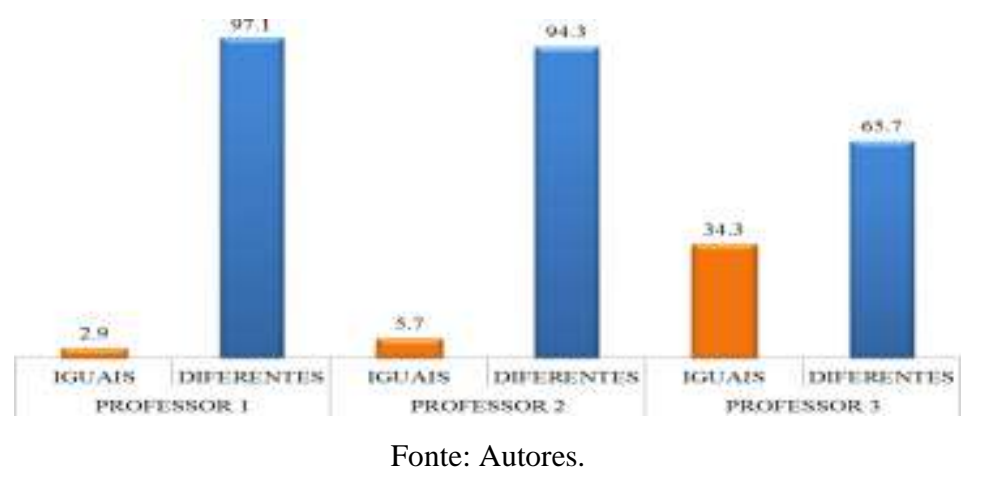

Contudo, fez-se necessário identificar em quais professores esta classificação apresenta associação entre as leituras (Tabela 4). Por meio da Partição do Qui-quadro $\left(\mathrm{X}^{2}\right)$ verificou-se que as professoras P1 e P2 apresentam porcentagem maior de análise de leituras classificadas como diferentes quando comparas ao P3 (95,7\% versus 65,7\%; p<0,001). 
Tabela 4. Número e percentual de juízes segundo comparação na classificação da leitura. Análise da Partição do $X^{2}$.

\begin{tabular}{|c|c|c|c|c|}
\hline Comparações & Leituras & $\mathbf{P 1}+\mathbf{P 2}$ & $\mathbf{P 3}$ & $\mathbf{p}$ \\
\hline & & n (\%) & n (\%) & \\
\hline \multirow[t]{2}{*}{ Partição } & Iguais & $3(4,3)$ & $12(34,3)$ & $<0,001$ \\
\hline & Diferentes & $67(95,7)$ & $23(65,7)$ & \\
\hline Total & & $70(100,0)$ & $35(100,0)$ & \\
\hline \multirow[t]{4}{*}{ Estratificação 1} & Leituras & P1 & P2 & $\mathbf{p}$ \\
\hline & & n (\%) & n (\%) & \\
\hline & Iguais & $1(2,9)$ & $2(5,7)$ & 1,000 \\
\hline & Diferentes & $34(97,1)$ & $33(94,3)$ & \\
\hline \multirow[t]{4}{*}{ Estratificação 2} & Leituras & P1 & P3 & $\mathbf{p}$ \\
\hline & & n (\%) & n (\%) & \\
\hline & Iguais & $1(2,9)$ & $12(34,3)$ & 0,001 \\
\hline & Diferentes & $34(97,1)$ & $23(65,7)$ & \\
\hline \multirow[t]{4}{*}{ Estratificação 3} & Leituras & P2 & P3 & $\mathbf{p}$ \\
\hline & & n (\%) & n $(\%)$ & \\
\hline & Iguais & $2(5,7)$ & $12(34,3)$ & 0,003 \\
\hline & Diferentes & $33(94,3)$ & $23(65,7)$ & \\
\hline Total & & $35(100,0)$ & $35(100,0)$ & \\
\hline
\end{tabular}

Fonte: Autores.

A Tabelas 5 apresenta a análise dos descritores, considerando cada descritor apresentado. Verifica-se que em P1 somente o descritor clara não apresentou mudança estatisticamente significativa na leitura pré e pós a intervenção ( $p=0,864)$.

Quanto às demais variáveis, destaca-se a leitura melodiosa $(\mathrm{p}=0,024)$. Dos 11 juízes que julgaram a voz mais melodiosa do P1 na avaliação pré, após a intervenção 10 verificaram uma piora e um registrou que permanecia com o mesmo status. Por outro lado, dos 24 classificados como menos melodiosa, 100,0\% passaram a mais melodiosa no momento pós intervenção (Tabela 5). 
Research, Society and Development, v. 10, n. 15, e557101520095, 2021

(CC BY 4.0) | ISSN 2525-3409 | DOI: http://dx.doi.org/10.33448/rsd-v10i15.20095

Tabela 5. Avaliação da mudança das características da leitura para as Professora (P1-P3).

\begin{tabular}{|c|c|c|c|c|c|}
\hline \multirow{3}{*}{\multicolumn{2}{|c|}{$\begin{array}{l}\text { Características da leitura (P1) } \\
\text { Pré }\end{array}$}} & \multicolumn{2}{|c|}{ Pós } & \multirow{3}{*}{ Total } & \multirow{3}{*}{$\mathrm{p}$} \\
\hline & & - & + & & \\
\hline & & $\mathrm{n}(\%)$ & $\mathrm{n}(\%)$ & & \\
\hline \multirow[t]{2}{*}{ Cativante } & + & $6(85,7)$ & 1 & 7 & $<0,001$ \\
\hline & - & 0 & $28(100,0)$ & 28 & \\
\hline \multirow[t]{2}{*}{ Motivante } & + & $5(83,3)$ & 1 & 6 & $<0,001$ \\
\hline & - & 0 & $29(100,0)$ & 29 & \\
\hline \multirow[t]{2}{*}{ Interessante } & + & $5(83,3)$ & 1 & 6 & $<0,001$ \\
\hline & - & 0 & $29(100,0)$ & 29 & \\
\hline \multirow[t]{2}{*}{ Clara } & + & $18(100,0)$ & 0 & 18 & 0,864 \\
\hline & - & 1 & $16(94,1)$ & 17 & \\
\hline \multirow[t]{2}{*}{ Melodiosa } & + & $10(90,9)$ & 1 & 11 & 0,024 \\
\hline & - & 0 & $24(100,0)$ & 24 & \\
\hline \multirow[t]{2}{*}{ Pausada } & + & $8(100,0)$ & 0 & 8 & 0,003 \\
\hline & - & 1 & $26(96,3)$ & 27 & \\
\hline \multirow{2}{*}{\multicolumn{2}{|c|}{ Características da leitura (P2) }} & \multicolumn{2}{|c|}{ Pós } & & \\
\hline & & - & + & Total & $\mathrm{p}$ \\
\hline Pré & & $\mathrm{n}(\%)$ & $\mathrm{n}(\%)$ & & \\
\hline \multirow[t]{2}{*}{ Cativante } & + & $3(75,0)$ & 1 & 4 & $<0,001$ \\
\hline & - & 1 & $30(96,8)$ & 31 & \\
\hline \multirow[t]{2}{*}{ Motivante } & + & $3(75,0)$ & 1 & 4 & $<0,001$ \\
\hline & - & 1 & $30(96,8)$ & 31 & \\
\hline \multirow[t]{2}{*}{ Interessante } & + & $2(66,7)$ & 1 & 3 & $<0,001$ \\
\hline & - & 1 & $31(96,9)$ & 32 & \\
\hline \multirow[t]{2}{*}{ Clara } & + & $5(83,3)$ & 1 & 6 & $<0,001$ \\
\hline & - & 1 & $28(96,6)$ & 29 & \\
\hline \multirow[t]{2}{*}{ Melodiosa } & + & $3(75,0)$ & 1 & 4 & $<0,001$ \\
\hline & - & 1 & $30(96,8)$ & 31 & \\
\hline \multirow[t]{2}{*}{ Pausada } & + & $5(83,3)$ & 1 & 6 & $<0,001$ \\
\hline & - & 1 & $28(96,6)$ & 29 & \\
\hline \multirow{2}{*}{\multicolumn{2}{|c|}{ Características da leitura (P3) }} & \multicolumn{2}{|c|}{ Pós } & & \\
\hline & & - & + & Total & $\mathrm{p}$ \\
\hline Pré & & $\mathrm{n}(\%)$ & $\mathrm{n}(\%)$ & & \\
\hline \multirow[t]{2}{*}{ Cativante } & + & $3(42,9)$ & 4 & 7 & $<0,001$ \\
\hline & - & 8 & $20(71,4)$ & 28 & \\
\hline \multirow[t]{2}{*}{ Motivante } & + & $4(50,0)$ & 4 & 8 & 0,003 \\
\hline & - & 8 & $19(70,4)$ & 27 & \\
\hline \multirow[t]{2}{*}{ Interessante } & + & $4(50,0)$ & 4 & 8 & 0,003 \\
\hline & - & 8 & 27 & $19(70,4)$ & \\
\hline \multirow[t]{2}{*}{ Clara } & + & $2(33,3)$ & 4 & 6 & $<0,001$ \\
\hline & - & 8 & $21(72,4)$ & 29 & \\
\hline Melodiosa & + & $5(55,6)$ & 4 & 9 & 0,011 \\
\hline & - & 8 & $18(69,2)$ & 26 & \\
\hline Pausada & + & $4(57,1)$ & 3 & 7 & $<0,001$ \\
\hline & - & 9 & $19(67,9)$ & 28 & \\
\hline
\end{tabular}

Fonte: Autores. 
A Tabela 6 ilustra a avaliação dos resultados na perspectiva das três participantes. Ressalta-se que todas relataram ter obtido conhecimentos em todos os recursos vocais trabalhados na intervenção, a saber: respiração, articulação, ressonância, pitch e intensidade. Observa-se que a respiração foi um aspecto que relatado tanto quando se referiram aos conhecimentos novos obtidos (P1) e quanto ao que foi colocado em prática (P1 e P3). Verifica-se que o tempo poderia ter sido maior de acordo com P1 e P2.

Tabela 6 - Avaliação dos resultados na perspectiva das participantes.

\begin{tabular}{|c|c|c|c|}
\hline Sujeito/ Aspecto & P1 & P2 & $\mathbf{P 3}$ \\
\hline $\begin{array}{l}\text { Conhecimentos que } \\
\text { mais gostei }\end{array}$ & Importância da respiração & Entoação e pausa & Mudar a voz sem forçar \\
\hline Exercicio /Respiração & Narina alternada & $\begin{array}{l}\text { Inspira enche o abdomen e } \\
\text { expira narinas alternadas }\end{array}$ & $\begin{array}{l}\text { Respiração alternada } \\
\text { utilizando os dedos }\end{array}$ \\
\hline articulação & Todos foram bons & Falar mais exagerado & $\begin{array}{l}\text { Abrir bem a boca na } \\
\text { leitura }\end{array}$ \\
\hline ressonância & Todos foram bons & De passar a voz pelo nariz & Trazer a voz para o nariz \\
\hline $\begin{array}{l}\text { Pitch grave/agudo) } \\
\text { grossa/fina }\end{array}$ & Gostei de todos & $\begin{array}{l}\text { Como a mudança de } \\
\text { tonalidade pode ajudar no } \\
\text { lugar de aumentar o volume da } \\
\text { voz }\end{array}$ & Para aquecer \\
\hline intensidade & Gostei de todos & $\begin{array}{l}\text { Mais forte, mais suave, } \\
\text { projetar mais a voz }\end{array}$ & $\begin{array}{l}\begin{array}{l}\text { Contar } \\
\text { respiração }\end{array} \\
\text { durante }\end{array}$ \\
\hline Coloquei em prática & Respiração & Entoação e pausa & $\begin{array}{l}\text { Respiração } \\
\text { aquecimento }\end{array}$ \\
\hline $\begin{array}{l}\text { Dúvidas que não } \\
\text { foram esclarecidas }\end{array}$ & não & não & não \\
\hline $\begin{array}{l}\text { Tempo proposto foi } \\
\text { suficiente }\end{array}$ & não & $\begin{array}{l}\text { Sim, mas se tivesse mais seria } \\
\text { ainda melhor }\end{array}$ & $\operatorname{sim}$ \\
\hline $\begin{array}{lr}\text { Curso ajudou } & \text { a } \\
\text { melhorar } & \text { minha } \\
\text { expressividade } & \text { na } \\
\text { leitura } & \end{array}$ & $\begin{array}{l}\text { Sim, principalmente } \\
\text { quanto a usar outros } \\
\text { recursos que poupem a voz }\end{array}$ & $\begin{array}{l}\text { Sim, principalmente quanto a } \\
\text { melhor articulação }\end{array}$ & $\begin{array}{l}\text { Sim, principalmente } \\
\text { quanto a mudança de } \\
\text { vozes }\end{array}$ \\
\hline $\begin{array}{l}\text { Curso atingiu minhas } \\
\text { expectativas }\end{array}$ & $\begin{array}{l}\text { Sim, conheci novos } \\
\text { exercícios }\end{array}$ & Sim & $\begin{array}{l}\text { Sim, as dinâmicas } \mathrm{e} \\
\text { exercícios }\end{array}$ \\
\hline
\end{tabular}

Fonte: Autores.

\section{Discussão}

O objetivo deste estudo foi verificar os efeitos de uma proposta de intervenção realizada por um fonoaudiólogo, com foco na expressividade oral, para melhorar a leitura em voz alta de três professoras. A análise dos efeitos dessa intervenção foi realizada por 35 juízes também professores com experiência docente, em sua maioria, em educação infantil.

A intervenção buscou desenvolver dinâmicas de aprimoramento dos recursos de expressividade oral e o objetivo principal foi orientar e sensibilizar as participantes sobre a importância de uma leitura de história de forma clara e motivadora para crianças. Conforme previsto nos recursos metodológicos (Ferreira, 2015), as atividades realizadas permitiram a vivência de recursos vocais e, dentre elas, a auto-observação e observação dos grupos. O intuito dessa estratégia foi facilitar que o sujeito falasse sobre si mesmo a partir do que via. Assim, por meio da audição das próprias performances, puderam fazer um intercâmbio das impressões das mesmas no grupo. Tomou-se o cuidado de trabalhar a percepção do que são ajustes inadequados para evitá-los, como também o quanto o uso de algumas práticas pode auxiliar no bem-estar vocal.

A seleção de juízes atuantes em sua maioria em educação infantil baseou-se na pressuposição de que a experiência docente com crianças faria com que esses professores apresentassem uma maior percepção do que é uma leitura interessante e mais motivadora para esse público. 
Os resultados de estudo de efeitos da expressividade de leitura revelaram que crianças de educação infantil apresentaram diferença estatisticamente melhor no teste de compreensão da história quando ouviram a leitura com mais recursos vocais de expressividade (Cordeiro, 2015; Tozzo, 2017). Esse fato reforça a importância do desenvolvimento de programas de intervenção para professores de educação infantil.

Corroborando essa perspectiva, um estudo comparou os efeitos de dois programas de aperfeiçoamento da comunicação oral para estudantes de comunicação, sendo que em um grupo foi trabalhada a voz para a comunicação oral e no outro, a expressividade verbal para a comunicação oral. Ao final, os resultados apontaram um efeito positivo do treinamento nos dois grupos estudados. Houve diferença entre os momentos pré e pós-treinamento em todas as medidas avaliadas, sendo que as leituras consideradas como melhores correspondiam às emissões pós-intervenção (Borrego, 2017).

Observou-se aumento das medidas de duração de tempo, durante leitura do enunciado, nas três participantes depois da intervenção fonoaudiológica (Tabela 3). Cada falante possui um tempo intrínseco próprio, e essa taxa depende de cada um dos falantes. Há falantes, que, por natureza, falam mais rápido do que outros (Meireles, 2009). Por outro lado, as mudanças na duração também podem estar relacionadas ao uso de recursos expressivos, como parece ter acontecido neste estudo. Observouse aumento das medidas de duração de tempo do enunciado em todas participantes, depois que as mesmas variaram o uso de recursos de expressividade oral praticados na intervenção. Contudo, por não ser o objetivo deste estudo realizar a avaliação acústica dos parâmetros, não se pode afirmar quais recursos determinaram esse aumento. Em pesquisa que analisou a expressividade oral, a professora que falou rápido teve a fala considerada desagradável pelos alunos juízes (Ferreira et al., 2012). Nesse estudo, a duração foi um aspecto valorizado pelos alunos, e determinante na escolha da ordem de preferência da fala das professoras. Outro estudo revelou que quando fonoaudiólogas narravam uma história para um grupo de crianças pequenas, falavam mais devagar do que para crianças de 12 anos (Sheng et al., 2003), fato que evidencia que sem perceber, as profissionais falam mais devagar para crianças menores.

Conforme observa-se na classificação referente à leitura das professoras pré e pós-intervenção como iguais ou diferentes, segundo professor (Tabela 4), a maioria dos juízes notou diferença entre os dois momentos em todas participantes. Entretanto, para P3, as mudanças foram percebidas em menor porcentagem quando comparadas as das demais participantes (P3 - 65.7\% dos juízes, enquanto para P1 e P2 aproximadamente 95\%). Cabe destacar que durante a realização da intervenção P3 foi a que se mostrou mais tímida, frente à realização das estratégias apresentadas. Durante os encontros, foi frequente observar que P3 lia com intensidade reduzida, não se voluntariou para começar as dinâmicas e se colocava somente quando chamada. P1 e P2 espontaneamente fizeram comentários e trouxeram referências do seu dia a dia. P1, por exemplo, se destacou por fazer observações sobre a leitura das outras participantes do grupo e até sugerir outros exemplos, formas e sentidos de leitura. Sabe-se que a possibilidade de cada pessoa observar a si mesma e ao grupo pode causar transformações na expressividade oral (Ferreira et al., 2012).

P3 foi também a participante que registrou menor variação nas medidas de duração do enunciado na comparação entre os momentos pré e pós-intervenção, com diferença mínima de aproximadamente um segundo (Tabela 1). Em um momento, quando questionada sobre a percepção que tinha da própria articulação, relatou ter impressão de falar muito rápido, "principalmente no final de frases". Em uma ocasião numa dinâmica de intenções das personagens, essa professora fez um comentário sobre pessoas que às vezes querem falar uma ordem, mas na verdade soam como se estivessem fazendo um pedido. Parece que P3 se identificou com esse exemplo e talvez apresente dificuldade em expressar oralmente suas intenções em alguns momentos. Características da expressividade oral não são dissociadas da personalidade. Há pessoas mais simbólicas no uso dos sons do que outras (Sapir, 1929). A variação da duração de tempo é um recurso que expressa personalidade do falante, presente também no contador, que imprime ritmos variados à história e, assim, sugere situações e subtextos (Barrichelo, 2013). Portanto, é natural que se observe maior variação de uso de recursos praticados nas professoras que apresentaram menos 
reservas em realizar as dinâmicas propostas e "ousaram" mais nas mudanças de vozes das personagens. Uma leitura fluente também depende de uma taxa de elocução apropriada, e a expressividade da leitura causa impacto no engajamento dos ouvintes e na motivação para leitura (Rasinski, 2009). A melodia de uma frase entoacional é o resultado de uma variedade de forças que expressa a participação afetiva do falante.

Pode-se hipotetizar que apesar de ter sido registrada mudança estatisticamente significativa para todos os professores, talvez para P3, com característica de personalidade mais reservada, uma intervenção demande mais tempo e mais encontros, do que os colocados em prática neste estudo (seis horas, seis encontros de uma hora cada). É interessante observar, porém que somente P3 não percebeu a necessidade de maior tempo para futuras propostas de intervenção como a deste estudo.

Por meio de análise estatística, verificou-se que as professoras P1 e P2 apresentaram leituras classificadas como diferentes em porcentagem maior quando comparas ao P3 (95,7\% versus $65,7 \%$; $<<0,001)$.

Pode-se observar que a maior parte dos juízes, que perceberam diferenças entre os dois momentos da intervenção, preferiram o momento pós como mais cativante, interessante, motivador, pausado e melodioso. A única exceção foi para o descritor: clara, em P1, que não apresentou mudança significativa entre as leituras (pré/pós). No entanto, para os outros participantes houve mudança estatisticamente significativa para todos os descritores. Dessa forma, pôde-se justificar o quanto uma intervenção, fundamentada na literatura e nas pesquisas, pode contribuir para o desenvolvimento e capacitação na expressividade de professores da educação infantil. A inflexão de vários tons pode criar uma entoação que desenha curvas melódicas. Dependendo do desenho, o resultado define diferentes intenções e sentidos. Os estados emocionais das personagens precisam ser representados por entoações, e, pela experiência dos próprios ouvintes, fica fácil identificá-los (Rasinski, 2009). Ler é uma prática discursiva e um processo de produção de sentidos (Pastorello, 2010). Geralmente caracteriza-se a fala como expressiva quando esta apresenta variabilidade de padrões melódicos e rítmicos. O termo "efeitos de sentido", é usado nesse contexto para sinalizar que a matéria fônica causa impressões nos ouvintes, os quais the atribuem sentidos (Madureira, 2011). Foi esse aspecto - atribuição de sentidos - que foi analisado neste estudo, quando os juízes fizeram uso de descritores prédeterminados para avaliarem as mudanças ocorridas nos dois momentos da intervenção.

As respostas da avaliação na perspectiva das três participantes mostram que após a intervenção as participantes revelaram terem obtido novos conhecimentos em relação à expressividade e colocaram esses em prática. Apontaram terem conhecido novos recursos para mudanças de suas vozes em contexto de leitura. Para as professoras, conforme o que referiram, os efeitos positivos da intervenção foram percebidos em todos aspectos de expressividade oral trabalhados (em quesitos diferentes para cada uma). P2 utilizou as palavras entoação e pausas ao referir novos conhecimentos obtidos e também colocados em prática. Esses achados estão registrados de acordo com os juízes quando apontaram como mais pausada a leitura realizada pós-intervenção em todas as participantes. Em especial em P2, 82.9\% dos juízes perceberam a leitura como mais pausada depois da intervenção.

As professoras também observaram que recursos de expressividade oral podem ser utilizados a serviço da saúde vocal quando responderam que o curso as ajudou a "poupar a voz" (P1) e "não forçar" (P3). Um dos resultados da oficina foi o uso com maior conhecimento de bem-estar vocal em sala de aula. Os exercícios respiratórios e de coordenação pneumofonoarticulatória foram mencionados na avaliação feita pelos participantes. O participante P3 usou a expressão "contar durante a respiração" para explicar a ampliação de sua capacidade respiratória. Uma hipótese é de que talvez o aumento das medidas de duração de enunciado tenha sido resultado também dessas dinâmicas.

Tais fatos apontam para a necessidade de o fonoaudiólogo rever seu olhar nas questões de trabalho com professor. Muitos professores alegam que as recomendações do fonoaudiólogo acabam limitando-se à importância de ingerir água e maçã. Dessa forma, seria interessante apresentar propostas como a deste estudo para esses profissionais perceberem que ao 
trabalhar a expressividade oral podem de forma paralela cuidar da voz. Destaca-se também a importância dessa experiência ser benéfica pelo fato de que variar a forma de falar causa efeitos nos alunos.

Ao se refletir sobre os resultados, acredita-se que a intervenção promoveu um impacto positivo nas professoras, pois despertou o interesse em continuar realizando os exercícios e a auto-observação de ajustes que "forçam a voz". Um dos resultados da oficina foi segundo relato das participantes, o uso com maior conhecimento em sala de aula. Certamente o programa aqui proposto, alcançou seu objetivo de sensibilizar as envolvidas e provocar mudanças na expressividade oral durante leitura de histórias, que de acordo com os resultados, agora estão mais interessantes e motivadoras para crianças pequenas.

Acredita-se que os procedimentos adotados foram aceitos pelas participantes, indo na direção da necessidade de seus interesses, e que o conteúdo selecionado foi pertinente para o contexto de uso da voz durante leitura de histórias. Entretanto, verificou-se a necessidade de um tempo maior para executar todas as atividades propostas.

É importante destacar ainda que a coleta de dados deste estudo possibilita realizar futuras análises como a acústica, a perceptivo-auditiva realizada, bem como o registro vocal. Além disso, pode-se hipotetizar diferentes resultados se forem selecionadas para serem juízes desse material crianças de uma faixa etária um pouco maior que as do público selecionado neste estudo, ou mesmo contadores de história.

Importante salientar que a proposta ora analisada priorizou apenas a expressividade oral, mais presente na atividade de ler histórias em voz alta. Contudo analisar aspectos de expressividade corporal é necessária uma vez que as duas instânciasoral/corporal estão presentes na atividade de narrativas, principalmente na contação de histórias.

\section{Conclusão}

Uma intervenção realizada por fonoaudiólogo pautada em estratégias relacionadas à respiração, recursos de expressividade oral e linguísticos propiciou diferença na expressividade oral de professoras em situação de leitura em voz alta, registrada, no momento pós-intervenção, pelo aumento da duração dos enunciados bem como julgamento positivo da maioria dos juízes, principalmente quanto a estar mais pausada, melodiosa, interessante, cativante e motivadora para o público infantil.

Considerando os problemas de leitura constatados em alunos cursando o Ensino Fundamental, futuras pesquisas com procedimentos metodológicos semelhantes aos apresentados neste artigo poderão analisar os efeitos em crianças que dominam a decodificação das palavras, mas tem dificuldade com o manejo das habilidades de leitura, para melhor entendimento do texto.

\section{Referências}

Azevedo, J. B. M., Ferreira, L. P., \& Kyrillos, L. R. (2009) Julgamento de telespectadores a partir de uma proposta de intervenção fonoaudiológica com telejornalistas. Rev CEFAC, 11(2):281-9.

Barrichelo, V. (2013). A voz do contador de histórias teia de experiências teia de experiências. 60-61.

Bolinger, D. (1961). Contrasti ve accent and contrastive stress. Language.

Borrego, M. C. M. (2017). Proposta de atuação fonoaudiológica para estudantes de comunicação: efeitos de dois tipos de treinamento. Tese. Universidade Federal de São Paulo. Escola Paulista de Medicina. São Paulo, SP, Brasil.

Chartier, R., (1997). Leituras e Leitores "populares” da Renascença ao Período Clássico in Cavallo, G \& Chartier, R. História da Leitura no Mundo Ocidental. Ática, p.26-33.

Clot, Y. (2002). La fonction psychologique du travail. Troisième édition augmentée. Presses Universitaires de France.

Combs, M., \& Beach, J. D. (1994). Stories and storytelling: Personalizing the social studies. The Reading Teacher, 47(6): 464-473. 
Cordeiro, C. O. (2015). Leitura de história em voz alta: uma proposta de intervenção fonoaudiológica com professores. Dissertação de Mestrado. Pontifícia Universidade Católica de São Paulo, São Paulo, SP, Brasil.

Druce, A. Bruxa, bruxa: venha a minha festa. (1995). Ilustração de Pat Ludlow. Brinque-book.

Ferreira, L. P., Arruda, A. F., \& Serrano-Marquezin, D. M. S. (2012) Expressividade oral de professoras: análise de recursos vocais. Rev Distúrbios da Comunicação, 24 (2): 223-37.

Forrin, N., \& Macleod, C. M. (2018). This time it's personal: the memory benefit of hearing oneself. Memory. 26(4):574-579. 10.1080/09658211.2017.1383434. Epub 2017 Oct 2

Groen, M. A., Veenendaal, N. J., \& Verhoeven, L., (2018). The role of prosody in reading comprehension: evidence from poor comprehenders: Prosody and Reading Comprehension. Journal of Research in Reading. 42(1), 37-57. 10.1111/1467-9817.12133.

Hochman. B., Nahas, F.X., Oliveira, R. S. F., \& Ferreira, L. M. (2005). Desenhos de pesquisa. Acta Cir Bras, 20 Suppl. 2:02-9. 10.1590/S010286502005000800002 .

Hudson, R. F., Lane, H. B., \& Pullen, P. C. (2005). Reading Fluency assessment and instruction: What, why, and how? International Reading Association, 702-714.

Hutton, J. S., Horowitz-Kraus, T., DeWitt, T., \& Holland, S. (2017). Parent-Child Reading Increases Activation of Brain Networks Supporting Emergent Literacy in 3-5 Year-Old Children: An fMRI study. Acta Paediatrica, 107(4): 685-693.

Hutton, J. S., Dudley, J., Horowitz-Kraus, T., DeWitt, T., \& Holland, SK. (2020) JAMA Pediatr. 1;174(1):e193869. 10.1001/jamapediatrics.2019.3869.

Kyrillos, L.C.R. (2004). Voz na mídia (rádio e televisão). Tratado de Fonoaudiologia. Rocca. Cap.13, p.151-165.

Logan, G. D. (1997). Automaticity and reading: Perspectives from the instance theory of automatization. Reading and Writing Quarterly, 13:123-146.

Madureira, S. (2011). The Investigation of Speech Expressivity. In: H. Mello; A. Panunzi; T. Raso (Eds). (Org.). Illocution, modality, attitude, information patterning and speech annotation. Firenze University Press, 01; 101-118.

Meireles, A. R., \& Barbosa, P. (2009). O papel da taxa de elocução nos processos dinâmicos de mudança lingüística. Rev con(textos) Linguísticos Vitória, 3: 91-116.

Mira, W. A., \& Schwanenflugel, P. J. (2013). The impact of reading expressiveness on listening comprehension of storybooks by prekindergarten children. Language, Speech and Hearing Services in Schools, 44: 183-194.

Morais, F. A. R. (2010). Expressividade na locução comercial radiofônica: análise dos efeitos de uma proposta de intervenção fonoaudiológica. Dissertação de Mestrado. Pontifícia Universidade Católica de São Paulo, São Paulo, SP, Brasil.

Nedel, L. W., \& Silveira, F. (2016). Os diferentes delineamentos de pesquisa e suas particularidades na terapia intensiva. Rev Bras Ter Intensiva, 28(3):256260. DOI: $10.5935 / 0103-507 X .20160050$

Pastorello, L. M. (2010). Leitura em voz alta e apropriação da linguagem escrita pela criança. Tese. Universidade de São Paulo. São Paulo, SP, Brasil.

Paz, M. S. (2007). Oralidade na escola e formação de leitor. Rev Boitatá.

Rasinski, T.V. (2009). Speed does matter in reading. The Reading Teacher, 54(2):146-151.

Sapir, E. A. (1929) study in phonetic symbolism. Journal of experimental psychology, 12: 225-239.

Scarpa, M. A. (2005). Criança e a prosódia: uma retrospectiva e novos desenvolvimentos. Cadernos de Estudos Linguísticos, 47:(1) e (2).

Sheng, L., \& Mcgregor, K. K, Xu, Y. (2003). Prosodic and lexical- sintactic aspects of the therapeutic register. Clinical Linguistics and Phonetics,17: 355-363.

Trindade, L. L. M. (2008). Julgamento do efeito de um programa de intervenção fonoaudiológica na expressividade oral de repórteres. Dissertação de Mestrado. Pontifícia Universidade Católica de São Paulo, São Paulo, SP, Brasil.

Tozzo, A. P, T. (2017). Leitura em voz alta: julgamento de crianças quanto aos parâmetros de expressividade oral utilizados pelo professor. Dissertação de Mestrado. Pontifícia Universidade Católica de São Paulo, São Paulo, SP, Brasil.

Viola, I. C., Ghirardi, A. C. A. M., \& Ferreira, L. P. (2011). Expressividade no rádio: a prática fonoaudiológica em questão. Rev Soc Fras Fonoaudiol. 16(1):64-72.

Viola, I., \& Ferreira, L. P. Sonoridades. (2016). Dez Tópicos Sobre Expressividade Oral para o Fonoaudiólogo: uma Proposta de Debate. E-book. 